\title{
Application of AHP, Fuzzy AHP and PROMETHEE Method in Solving Additive Manufacturing Process Selection Problem
}

\author{
Ivan PEKO, Nikola GJELDUM, Boženko BILIĆ
}

\begin{abstract}
Additive manufacturing is a technology of making a three-dimesional solid object of any shape from a digital model. Today on the global market exist various additive manufacturing processes. All of these processes build parts by applying material layer by layer. In a wide range of different processes there is a problem of selecting an adequate process for a user or company interested in additive manufacturing technology. Solving of such a problem is possible by using multicriteria decision methods which result in ranking of alternatives. Thus the user or company can easily select one of the available additive manufacturing processes. In this paper basic methodology of application of three different multicriteria decision methods in solving the mentioned problem was shown. These methods are: Analytic hierarchy process (AHP), Fuzzy AHP and Preference ranking organization method (PROMETHEE). Available alternatives are processes: 3D printing, Fused Deposition Modeling, Selective Laser Sintering and Photopolymer Jetting
\end{abstract}

Keywords: additive manufacturing; AHP; Fuzzy AHP; PROMETHEE; selection problem

\section{INTRODUCTION}

By additive manufacturing (AM) technology it is possible to make products with complicated geometry in relatively short time. For that purpose 3D product model data developed by the Computer Aided Design (CAD) is required. Additive manufacturing processes do not require machining technology processes planning, development of tools and molds, specific machining equipment, logistics and warehousing activities planning etc. It is necessary to know only the basic constraints of machine operation and the way the machine applies a material. Additive manufacturing technology has two key levels of application: rapid prototyping and rapid manufacturing.

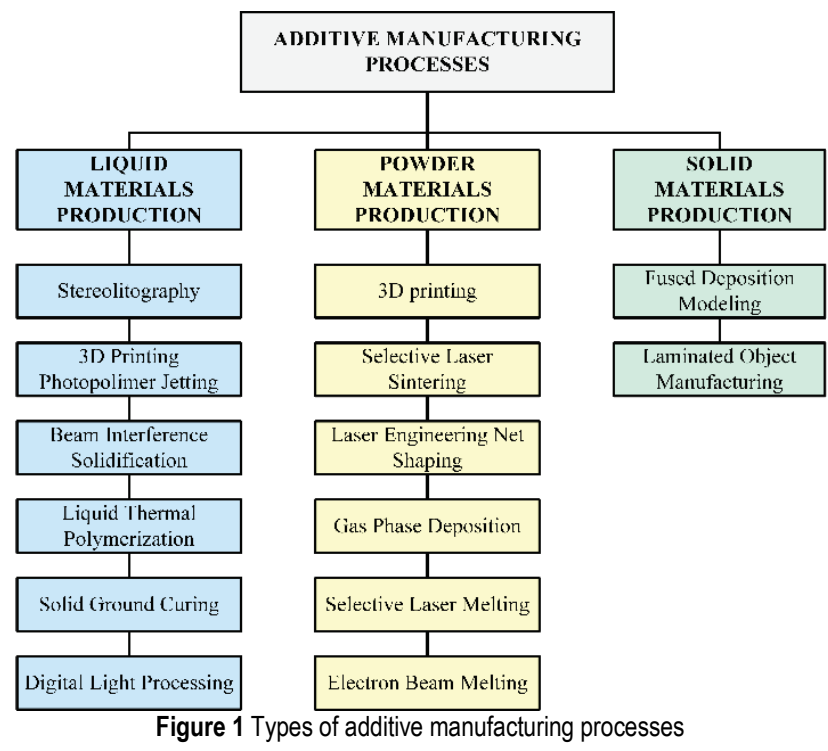

Rapid prototyping presents creating of conceptual prototypes that spatially show basic concept of some idea or innovation and functional prototypes that are used for evaluating quality and ergonomics properties and functions of future products. Rapid manufacturing generates fully functional finished products or tools which can be implemented in their practical application immediately after production process completion. Some of the basic advantages of additive technology are time shortening and cost lowering required for a new product development from initial concept to production start. Additive technology can help identify defects on workpieces whose elimination is more expensive when they reach serial production stage. Additive manufacturing processes can be divided into processes that use a building material in solid state (wire, sheet), liquid state and powder (Fig. 1). In such a wide range of different processes there is a problem of selecting an adequate additive manufacturing process for a user or company interested in additive manufacturing technology [1].

Many authors conducted researches using different multicriteria decision methods in solving decision problem between various alternatives ie. available additive manufacturing processes. Anderson Vincente Borille et al. [2] showed evaluation of three alternatives: the Fused Deposition Modeling, Selective Laser Sintering and conventional technology regarding quality, cost and process time criteria. For the decision process they used the Analytic hierarchy process (AHP) method. Byun et al. [3] used modified Technique for Order of Preference by Similarity to Ideal Solution (TOPSIS) method for ranking six rapid prototyping processes considering six different criteria: accuracy, surface roughness, tensile strength, elongation, part cost and build time. Shende et al. [4] also used the TOPSIS method and seven criteria: accuracy, surface finish, tensile strength, elongation, part cost, process time, heat deflection temperature, to rank four additive manufacturing processes: Stereolithography, Selective Laser Sintering, 3D Printing and Fused Deposition Modeling. Narayan Panda et al. [5] proposed integrated AHP and fuzzy TOPSIS approach for the selection of five rapid prototyping processes: Laminated Object Manufacturing, Selective Laser Sintering, 3D Printing, Fused Deposition Modeling and Stereolitography, regarding five criteria: dimensional accuracy, surface quality, part cost, build time and material properties. Lokesh K. et al. [6] developed AHP model based systematic approach to enable potential users to select the appropriate rapid prototyping technology.

In this paper a conceptual model of product (rotor) was built by four different additive manufacturing processes. Two of them use powder as a build material, one of them uses solid material (wire) and one liquid 
material (photoploymer jet). These processes are 3D Printing (3D PRINT), Fused Deposition Modeling (FDM), Selective Laser Sintering (SLS), Photopolymer Jetting (POLYJET). After the production process, for the purpose of mutual comparision of these processes, six different criteria are defined. These criteria are: dimensional accuracy, surface roughness, mechanical properties, process cost, process time and post-processing and they were obtained directly from manufacturing process. Solving selection problem of the most appropriate additive manufacturing process was conducted using three different multicriteria decision methods: the AHP, Fuzzy AHP and PROMETHEE method and methodology of their application in such a problem was shown step by step.

\section{PRODUCTION BY ADDITIVE MANUFACTURING PROCESSES}

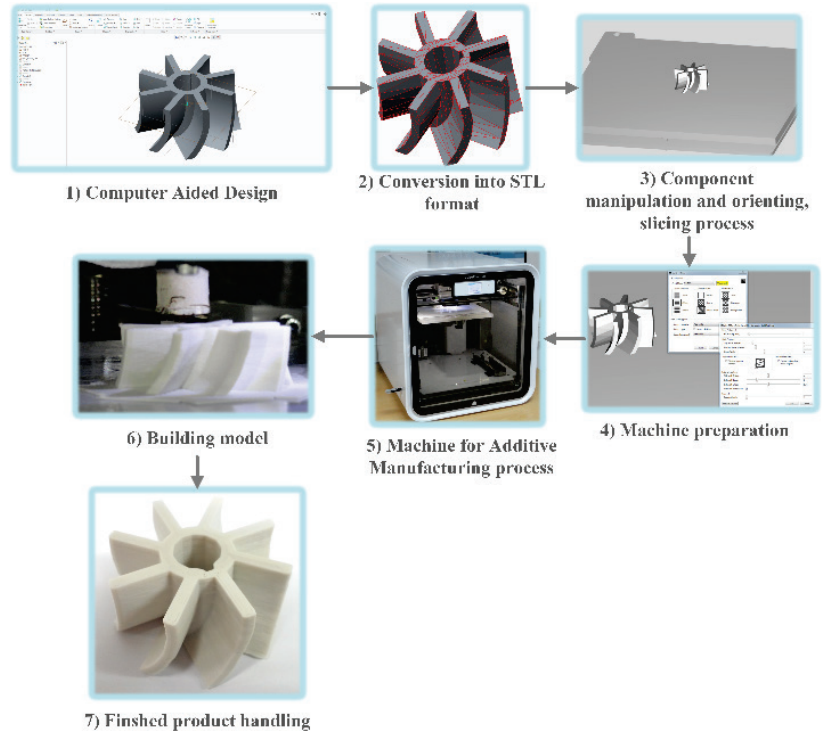

Figure 2 Additive Manufacturing process

Additive manufacturing process involves a number of steps that move from virtual CAD description to the physical part. These steps are (Fig. 2) [1]:
1) Computer Aided Design: All prototyped parts must start from a software model that fully describes the external geometry. This can involve the use of almost any professional CAD solid modeling software, but the output must be a 3D solid or surface representation. Reverse engineering equipment can also be used to create this representation.

2) Conversion to STL (STereoLitography) format: Nearly every machine for additive manufacturing accepts the STL file format, which has become de facto standard, and nearly every CAD system can output such a file format. This file describes the external closed surfaces of the original CAD model and forms the basis for calculation of the slices.

3) Transfer to machine and STL file manipulation: The STL file describing the part must be transferred to the AM machine. There may be some general manipulation of the file in order to put it into the correct size, position, and orientation for building.

4) Machine setup: The machine must be properly set up prior to the build process. Such settings would relate to the build parameters like the material constraints, energy source, layer thickness, timings, etc.

5) Build: Building the part is mainly an automated process and the machine can largely carry on without supervision.

6) Removal: Once the machine has completed the building, the parts must be removed. This may require interaction with the machine, which may have safety interlocks to ensure for example that the operating temperature is sufficiently low or that there are actively moving parts.

7) Postprocessing: Once removed from the machine, parts may require an amount of additional cleaning up before they are ready to use. Parts may be weak at this stage or they may have supporting features that must be removed. This often requires time and careful, experienced manual manipulation. However, they may also require additional treatment before they are acceptable for use or to be assembled together with other mechanical or electronic components to form a final model or product.

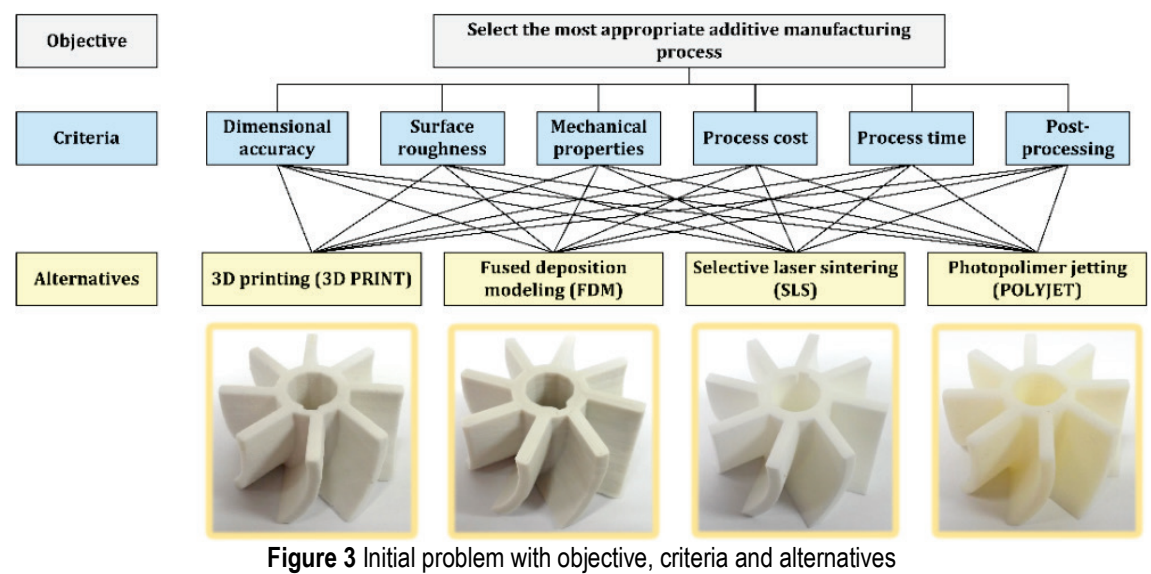

\section{APPLICATION OF MULTICRITERIA DECISION} METHODS

After the model production by mentioned additive manufacturing processes, the solving of decision making problem (Fig. 3) by multicriteria decision methods has been done. The AHP, Fuzzy AHP and PROMETHEE methods have been used. The objective is to show a basic methodology of application of these methods and to find out which of four additive manufacturing processes is 
most suitable for the user/company i.e. decision maker. The processes were compared with each other by six selected criteria. Each criterion has a specific numerical value. The data in Tab. 1. were obtained by measuring or in consultations with certain companies. Numerical values for dimensional accuracy criteria were obtained by measuring bore diameter with digital measuerement device, on each additive manufactured part. The measurements were performed in three iterations. The numerical value in the table is actually the mean value of measured data. The surface roughness data were obtained in the same way. Measurements of the surface roughness were performed on the flat forehead of the part on the top of the blades ( $x$ axis) without postprocessing. These measurements of surface roughness were performed by Taylor Hobson Surtronic 3 device. Mechanical properties data were taken from company catalogues that develop these additive manufacturing technologies and their materials [7-10]. Process cost, process time and postprocessing criteria values were acquired in cooperation with companies that are commercially involved in this technology. Process time values were obtained automatically from machine display. Post-processing values were obtained by measuring time required to clean up produced parts. All these data should be used as a start point for further application of multicriteria decision methods and output results greatly depend on them.

Table 1 Information available to the decision maker

\begin{tabular}{|c|c|c|c|c|c|c|}
\hline \multirow[b]{2}{*}{ Alternatives } & \multicolumn{6}{|c|}{ Criteria } \\
\hline & $\begin{array}{c}\text { Dimensional } \\
\text { accuracy } *\end{array}$ & $\begin{array}{c}\text { Surface } \\
\text { roughness** }\end{array}$ & $\begin{array}{c}\text { Mechanical } \\
\text { properties*** }\end{array}$ & $\begin{array}{l}\text { Process cost } \\
\text { (GBP) }\end{array}$ & $\begin{array}{l}\text { Process time } \\
\text { (min) }\end{array}$ & $\begin{array}{l}\text { Post-processing } \\
\text { (min) }\end{array}$ \\
\hline 3D PRINT & 0.38 & 7.48 & 27 & 55.00 & 66 & 8 \\
\hline FDM & 0.50 & 4.30 & 37 & 48.13 & 146 & 5 \\
\hline SLS & 0.17 & 6.82 & 48 & 137.90 & 195 & 13 \\
\hline POLYJET & 0.14 & 3.19 & 55 & 114.58 & 120 & 3 \\
\hline
\end{tabular}

* Deviation of bore diameter from the nominal value (in $\mathrm{mm}$ ); ** Measured surface roughness $R a$ (in $\mu \mathrm{m}$ ) in $x$ axis; *** Tensile strength (in MPa)

Table 2 Pairwise comparison matrix

\begin{tabular}{|c|c|c|c|c|c|c|}
\hline & $\begin{array}{c}\text { Dimensional } \\
\text { accuracy }\end{array}$ & Surface roughness & $\begin{array}{c}\text { Mechanical } \\
\text { properties }\end{array}$ & Process cost & Process time & Post-processing \\
\hline Dimensional accuracy & 1 & 1 & 3 & 7 & 9 & 7 \\
\hline Surface roughness & 1 & 1 & 3 & 7 & 9 & 7 \\
\hline Mechanical properties & $1 / 3$ & $1 / 3$ & 1 & 5 & 9 & 7 \\
\hline Process cost & $1 / 7$ & $1 / 7$ & $1 / 5$ & 1 & 3 & 3 \\
\hline Process time & $1 / 9$ & $1 / 9$ & $1 / 9$ & $1 / 3$ & 1 & 3 \\
\hline Post-processing & $1 / 7$ & $1 / 7$ & $1 / 7$ & $1 / 3$ & $1 / 3$ & 1 \\
\hline$\sum$ & 2.730 & 2.730 & 7.454 & 20.667 & 31.333 & 28.000 \\
\hline
\end{tabular}

Table 3 Calculated weights of criteria

\begin{tabular}{|c|c|c|c|c|c|c|c|}
\hline & $\begin{array}{c}\text { Dimensional } \\
\text { accuracy }\end{array}$ & $\begin{array}{c}\text { Surface } \\
\text { roughness }\end{array}$ & $\begin{array}{c}\text { Mechanical } \\
\text { properties }\end{array}$ & Process cost & Process time & Post-processing & $w$ \\
\hline Dimensional accuracy & 0.366 & 0.366 & 0.402 & 0.339 & 0.287 & 0.250 & 0.335 \\
\hline Surface roughness & 0.366 & 0.366 & 0.402 & 0.339 & 0.287 & 0.250 & 0.335 \\
\hline Mechanical properties & 0.122 & 0.122 & 0.134 & 0.242 & 0.287 & 0.250 & 0.193 \\
\hline Process cost & 0.052 & 0.052 & 0.027 & 0.048 & 0.096 & 0.107 & 0.064 \\
\hline Process time & 0.041 & 0.041 & 0.015 & 0.016 & 0.032 & 0.107 & 0.042 \\
\hline Post-processing & 0.052 & 0.052 & 0.019 & 0.016 & 0.011 & 0.036 & 0.031 \\
\hline$\sum$ & 1.000 & 1.000 & 1.000 & 1.000 & 1.000 & 1.000 & 1.000 \\
\hline
\end{tabular}

\begin{tabular}{|c|c|c|c|c||c|} 
Dimensional accuracy \\
\begin{tabular}{|c|c|c|c|c||c|}
\hline D.A. & 3D PRINT & FDM & SLS & POLYJEI & P \\
\hline 3D PRINT & 1 & 1.316 & 0.447 & 0.368 & 0.149 \\
\hline FDM & 0.760 & 1 & 0.340 & 0.280 & 0.113 \\
\hline SLS & 2.235 & 2.941 & 1 & 0.824 & 0.333 \\
\hline POI.YJFT & 2.714 & 3.571 & 1.214 & I & 0.405 \\
\hline$\Sigma$ & 6.710 & 8.828 & 3.002 & 2.472 & 1.000 \\
\hline
\end{tabular}
\end{tabular}

\begin{tabular}{|c|c|c|c|c||c|}
\hline S.R. & 3D PRINT & FDM & SLS & POLYJET & P \\
\hline 3D PRINT & 1 & 0.575 & 0.912 & $\mathbf{0 . 4 2 6}$ & 0.162 \\
\hline FDM & 1.740 & 1 & 1.587 & $\mathbf{0 . 7 4 2}$ & 0.281 \\
\hline SLS & 1.096 & 0.630 & $\mathbf{1}$ & $\mathbf{0 . 4 6 8}$ & 0.177 \\
\hline POLYJET & 2.345 & 1.348 & 2.139 & 1 & 0.379 \\
\hline$\Sigma$ & 6.181 & 3.553 & 5.638 & 2.636 & 1.000 \\
\hline
\end{tabular}
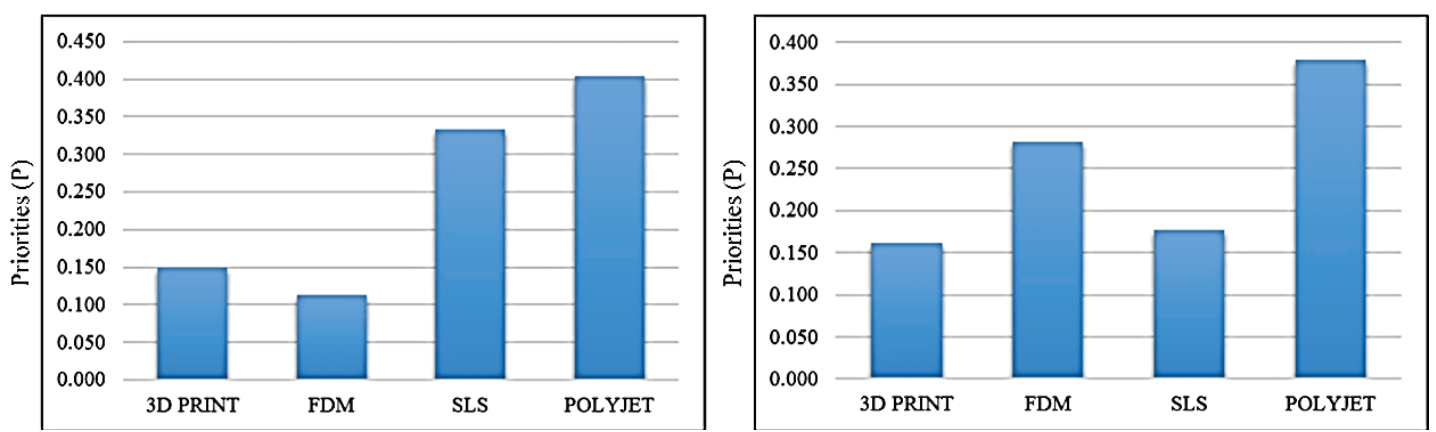

Figure 4 Ranking of alternatives for dimensional accuracy and surface roughness criteria 


\begin{tabular}{|c|c|c|c|c||c|}
\hline M.P. & 3D PRINT & FDM & SLS & POLYIET & P \\
\hline 3D PRINT & 1 & 0.730 & 0.563 & 0.491 & 0.162 \\
\hline FDM & 1.370 & 1 & 0.771 & 0.673 & 0.222 \\
\hline SLS & 1.778 & 1.297 & 1 & 0.873 & 0.287 \\
\hline POLYJET & 2.037 & 1.486 & 1.146 & 1 & 0.329 \\
\hline$\sum$ & 6.185 & 4.514 & 3.479 & 3.036 & 1.000 \\
\hline
\end{tabular}

Process cost
\begin{tabular}{|c|c|c|c|c||c|}
\hline P.C. & 3D PRINT & FDM & SLS & POLYJET & P \\
\hline 3D PRINT & 1 & 0.875 & 2.507 & 2.083 & 0.331 \\
\hline FDM & 1.143 & 1 & 2.865 & 2.381 & 0.378 \\
\hline SI.S & 0.399 & 0.349 & 1 & 0.831 & 0.132 \\
\hline POLYJET & 0.480 & 0.420 & 1.203 & 1 & 0.159 \\
\hline$\sum$ & 3.022 & 2.644 & 7.576 & 6.295 & 1.000 \\
\hline
\end{tabular}
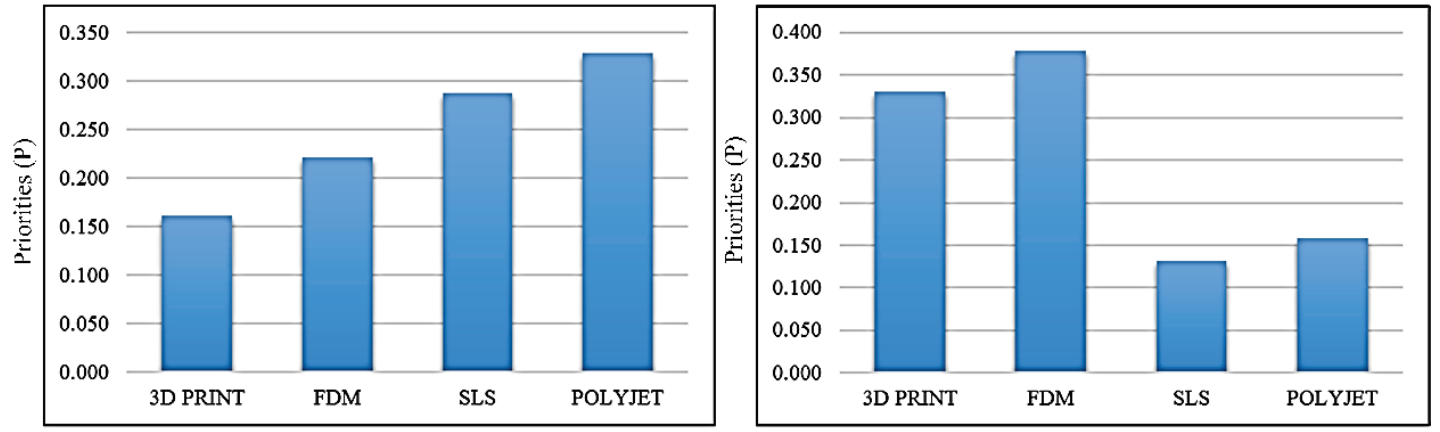

\begin{tabular}{|c|c|c|c|c||c|}
\hline P.T. & 3D PRINT & FDM & SLS & POLYJET & P \\
\hline 3D PRINI & 1 & 2.212 & 2.955 & 1.818 & 0.427 \\
\hline FDM & 0.452 & 1 & 1.336 & 0.822 & 0.193 \\
\hline SI.S & 0.338 & 0.749 & 1 & 0.615 & 0.145 \\
\hline POLYJEI & 0.550 & 1.217 & 1.625 & 1 & 0.235 \\
\hline$\sum$ & 2.341 & 5.178 & 6.915 & 4.255 & 1.000 \\
\hline
\end{tabular}

\begin{tabular}{|c|c|c|c|c||c|}
\multicolumn{1}{|c|}{ Post-processing } \\
\hline P.P. & 3D PRINT & FDM & SLS & POLYJET & P \\
\hline 3D PRINT & 1 & 0.625 & 1.625 & 0.375 & 0.170 \\
\hline FDM & 1.600 & 1 & 2.600 & 0.600 & 0.272 \\
\hline SLS & 0.615 & 0.385 & 1 & 0.231 & 0.105 \\
\hline POLYJET & 2.667 & 1.667 & 4.333 & 1 & 0.453 \\
\hline$\sum$ & 5.882 & 3.676 & 9.558 & 2.206 & 1.000 \\
\hline
\end{tabular}
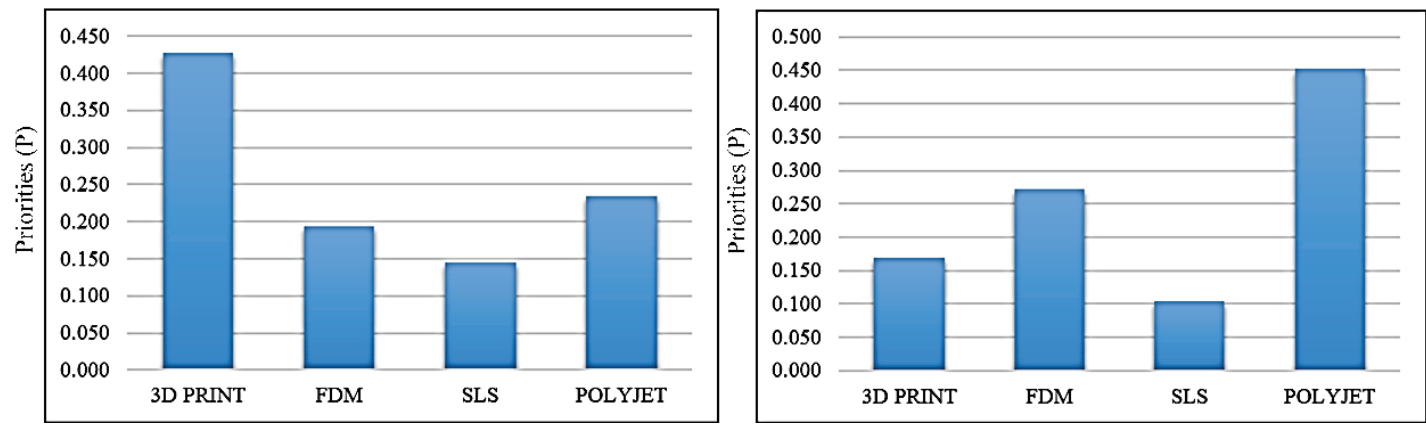

Figure 5 Ranking of alternatives for mechanical properties, process cost, process time and post-processing criteria

\subsection{AHP Method}

The AHP (Analytic Hierarchy Process) method [1113] was developed by Thomas Saaty in early 70 s of the last century. This is one of the most important decision methods which finds its application in solving complex problems consisting of the objective, criteria and alternatives. The application of the AHP method can be described in three basic steps:

1) Firstly, hierarchy model of decision making problem should be developed. That model should have its objective at the top, defined criteria at lower levels and available alternatives at the bottom of that model (Fig. 3).

2) On each level of the hierarchy structure elements should be compared in pairs one with each other. Preferences of the decision maker are expressed by Saaty's scale of relative importances which has 5 main stages and 4 intermediate stages of verbally described intensities and corresponding numerical values in the range of 1-9 (Tab. 2).

3) From the estimations of relative importances of elements from appropriate level of hierarchy structure using a mathematical model, weights of criteria and local priorities of alternatives can be obtained, which can be later synthesized in overall priorities of alternatives. Overall priority of each alternative can be calculated by summing its local priorities multiplied by weights of criteria.

An important feature in the application of the AHP method is consistency checking of decision maker's estimations. During comparisions of pairs of hierarchy structure elements, consistency of decision maker's estimations and determined correctness of obtained weights of criteria and priorities of alternatives should be checked.

Higher value of the Consistency Ratio $(C R)$ means that the decision maker is less consistent in his answers whereas lower value means the opposite. Generally, the Consistency Ratio has value 0.10 or less when the decision maker's answers are relatively consistent. If the Consistency Ratio is higher than 0.10 , the decision maker should again estimate the importances of criteria. In this case, the calculated Consistency Ratio fulfills the condition $C R \leq 0.10$.

The steps of the conducted AHP method are shown in Tab. 2 and Tab. 3 and in Fig. 4 and Fig. 5. The subjective evaluation of the decision maker and values from Saaty's scale have not been used to determine local priorities of 
alternatives according to each of criteria. Numerical values from initial table (Tab. 1) have been used instead. It can be concluded that hereby more accurate results and ranking of alternatives priorities were obtained because the possibility of decision maker's favoritism was excluded.

\subsection{Fuzzy AHP Method}

Since the standard AHP method does not include the possibility of situations with ambiguity in the estimation, it is possible to upgrade this method with fuzzy approach. This approach is called the Fuzzy AHP method [14]. Instead of one defined value, in the Fuzzy AHP method full range of values that include unsafe attitudes of decision maker should be generated. For that process it is possible to use triangular fuzzy numbers, trapezoidal or Gaussian fuzzy numbers. The Fuzzy AHP method suggests their application directly in criteria pairs comparison matrix. Triangular fuzzy numbers are used in most cases and because of that they have been applied in this paper also.

Triangular fuzzy number $\tilde{M}$ (Fig. 6) can be described as an interval of real numbers where each of them has a degree of belonging to the interval between 0 and 1 . Triangular fuzzy number is defined with three real numbers, expressed as $l, m$ and $u$.

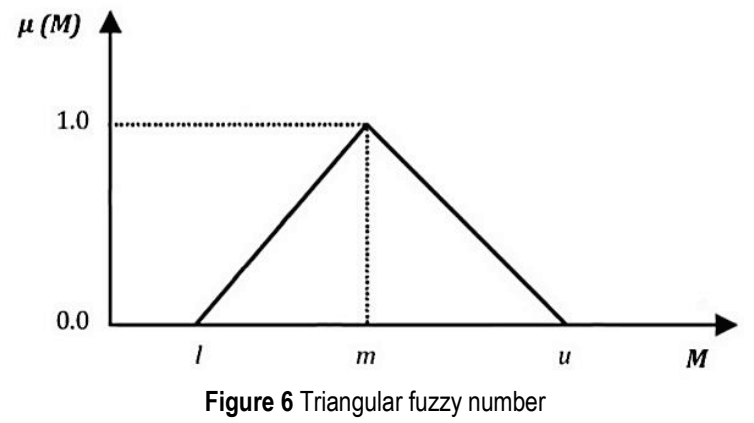

Parameters $l, m$ and $u$ present the lowest possible value, the most perspective value and the largest possible value described by fuzzy set. Their membership functions are given in Eq. 1 [14].

$\left(\frac{x}{\widetilde{M}}\right)=\left\{\begin{array}{cc}0, & x<l \\ (x-l) /(m-l), & l \leq x \leq m \\ (u-x) /(u-m), & m \leq x \leq u \\ 0, & x>u\end{array}\right\}$

The first step in solving problem by this method is replacing numerical values from Saaty's scale with triangular fuzzy numbers in the pairwise comparison matrix (Tab. 4). After forming a matrix of fuzzy criteria comparison it should be defined vector of criteria weights $W$. For that purpose the following equations were used [14].

The value of fuzzy synthetic extent is defined as:

$S_{i}=\sum_{j=1}^{m} M_{g i}^{j} \otimes\left[\sum_{i=1}^{n} \sum_{j=1}^{m} M_{g i}^{j}\right]^{-1}$

where

$\left[\sum_{i=1}^{n} \sum_{j=1}^{m} M_{g i}^{j}\right]^{-1}$

is computed with Eq. (3) and Eq. (4) as follows

$\sum_{j=1}^{m} M_{g i}^{j}=\left(\sum_{j=1}^{m} l_{j}, \sum_{j=1}^{m} m_{j}, \sum_{j=1}^{m} u_{j}\right)$

$\left[\sum_{i=1}^{n} \sum_{j=1}^{m} M_{g i}^{j}\right]^{-1}=\left(\frac{1}{\sum_{i=1}^{n} u_{i}}, \frac{1}{\sum_{i=1}^{n} m_{i}}, \frac{1}{\sum_{i=1}^{n} l_{i}}\right)$

$\widetilde{M_{1}}=\left(l_{1}, m_{1}, u_{1}\right)$ and $\widetilde{M_{2}}=\left(l_{2}, m_{2}, u_{2}\right)$ are two triangular fuzzy numbers (Fig. 6). The degree of possibility of $\widetilde{M_{1}}=\left(l_{1}, m_{1}, u_{1}\right) \geq \widetilde{M_{2}}=\left(l_{2}, m_{2}, u_{2}\right)$ can be defined as

$V\left(\widetilde{M_{2}} \geq \widetilde{M_{1}}\right)=$

$=\left\{\begin{array}{c}1, \text { if } m_{2} \geq m_{1} \\ 0, \text { if } l_{1} \geq u 2 \\ \frac{l_{1}-u_{2}}{\left(m_{2}-u_{2}\right)-\left(m_{1}-l_{1}\right)}, \text { otherwise }\end{array}\right\}$

Table 4 Fuzzy mutual criteria comparison

\begin{tabular}{|c|c|c|c|c|c|c|}
\hline & $\mathrm{C} 1$ & $\mathrm{C} 2$ & $\mathrm{C} 3$ & $\mathrm{C} 4$ & $\mathrm{C}$ & \multicolumn{1}{|c|}{ C6 } \\
\hline $\mathrm{C} 1$ & $(1,1,1)$ & $(1,1,1)$ & $(1,3,5)$ & $(5,7,9)$ & $(7,9,11)$ \\
\hline C2 & $(1,1,1)$ & $(1,1,1)$ & $(1,3,5)$ & $(5,7,9)$ & $(7,9,11)$ \\
\hline C3 & $(1 / 5,1 / 3,1)$ & $(1 / 5,1 / 3,1)$ & $(1,1,1)$ & $(3,5,7)$ & $(7,9,11)$ \\
\hline C4 & $(1 / 9,1 / 7,1 / 5)$ & $(1 / 9,1 / 7,1 / 5)$ & $(1 / 7,1 / 5,1 / 3)$ & $(1,1,1)$ & $(1,3,5)$ \\
\hline C5 & $(1 / 11,1 / 9,1 / 7)$ & $(1 / 11,1 / 9,1 / 7)$ & $(1 / 11,1 / 9,1 / 7)$ & $(1 / 5,1 / 3,1)$ & $(1,1,1)$ \\
\hline C6 & $(1 / 9,1 / 7,1 / 5)$ & $(1 / 9,1 / 7,1 / 5)$ & $(1 / 9,1 / 7,1 / 5)$ & $(1 / 5,1 / 3,1)$ & $(1 / 5,1 / 3,1)$ & $(1,3,5)$ \\
\hline
\end{tabular}

Fig. 7 illustrates Eq. (5). To compare $M 1$ and $M 2$ both values of $V\left(\widetilde{M_{1}} \geq \widetilde{M_{2}}\right)$ and $V\left(\widetilde{M_{2}} \geq \widetilde{M_{1}}\right)$ are required.

The degree possibility for a convex fuzzy number to be greater than $k$ convex fuzzy $M_{i}(i=1,2, k)$ numbers can be defined by

$$
\begin{aligned}
& V\left(\widetilde{M} \geq \widetilde{M_{1}}, \widetilde{M_{2}}, \ldots . \widetilde{M_{k}}\right)= \\
& =V\left[\left(\widetilde{M} \geq \widetilde{M_{1}}\right) i\left(\widetilde{M} \geq \widetilde{M_{2}}\right) i \ldots i\left(\widetilde{M} \geq \widetilde{M_{k}}\right)\right] \\
& =\min V\left(\widetilde{M} \geq \widetilde{M_{l}}\right), i=1,2,3, k
\end{aligned}
$$

Assume that $d\left(A_{i}\right)=\min V\left(S_{i} \geq S_{k}\right)$ for $k=$ $1,2, \ldots . n ; k \neq i$. Then the weight vector is given by

$W^{\prime}=\left(d^{\prime}\left(A_{1}\right), d^{\prime}\left(A_{2}\right), \ldots \ldots, d^{\prime}\left(A_{n}\right)\right)^{\mathrm{T}}$

where $A_{i}=(i=1,2, \ldots n)$ are $\mathrm{n}$ elements.

Via normalization, the normalized weight vector is

$W=\left(d\left(A_{1}\right), d\left(A_{2}\right), \ldots \ldots, d\left(A_{n}\right)\right)^{\mathrm{T}}$

where $W$ is a non-fuzzy number. 


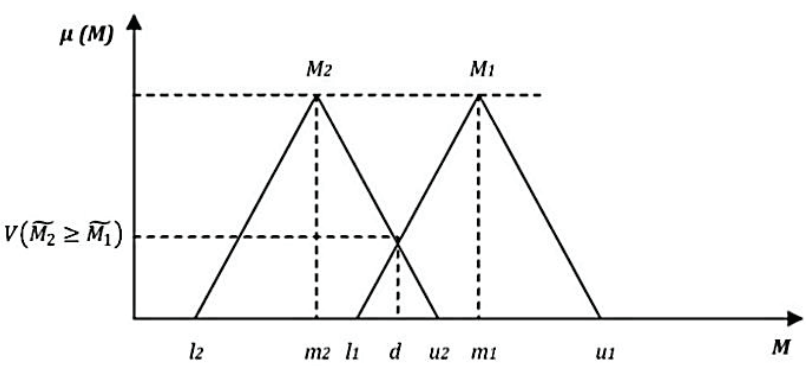

Figure 7 Intersection between $M_{1}$ and $M_{2}$ triangular fuzzy number

From Tab. 4, synthesis values with respect to the main goal were calculated like in Eq. (2):

$S_{C 1}=(0.16,0.30,0.56) ; S_{C 2}=(0.16,0.30,0.56) ;$

$S_{C 3}=(0.13,0.24,0.47) ; S_{C 4}=(0.027,0.08,0.18)$

$S_{C 5}=(0.02,0.05,0.12) ; S_{C 6}=(0.014,0.02,0.06)$;

These fuzzy values were compared by using Eq. (5) and the next values were obtained:

$V\left(S_{C 1} \geq S_{C 2}\right)=1 ; V\left(S_{C 1} \geq S_{C 3}\right)=1 ;$

$V\left(S_{C 1} \geq S_{C 4}\right)=1 ; V\left(S_{C 1} \geq S_{C 5}\right)=1$;

$V\left(S_{C 1} \geq S_{C 6}\right)=1$;

$V\left(S_{C 2} \geq S_{C 1}\right)=1 ; V\left(S_{C 2} \geq S_{C 3}\right)=1 ;$

$V\left(S_{C 2} \geq S_{C 4}\right)=1 ; V\left(S_{C 2} \geq S_{C 5}\right)=1$;

$V\left(S_{C 2} \geq S_{C 6}\right)=1$;

$V\left(S_{C 3} \geq S_{C 1}\right)=0.83 ; V\left(S_{C 3} \geq S_{C 2}\right)=0.83$;

$V\left(S_{C 3} \geq S_{C 4}\right)=1 ; V\left(S_{C 3} \geq S_{C 5}\right)=1$;

$V\left(S_{C 3} \geq S_{C 6}\right)=1$;

$V\left(S_{C 4} \geq S_{C 1}\right)=0.083 ; V\left(S_{C 4} \geq S_{C 2}\right)=0.083$;

$V\left(S_{C 4} \geq S_{C 3}\right)=0.24 ; V\left(S_{C 4} \geq S_{C 5}\right)=1$;

$V\left(S_{C 4} \geq S_{C 6}\right)=1$;

$V\left(S_{C 5} \geq S_{C 1}\right)=0 ; V\left(S_{C 5} \geq S_{C 2}\right)=0$;

$V\left(S_{C 5} \geq S_{C 3}\right)=0 ; V\left(S_{C 5} \geq S_{C 4}\right)=0.76$;

$V\left(S_{C 5} \geq S_{C 6}\right)=1$;

$V\left(S_{C 6} \geq S_{C 1}\right)=0 ; V\left(S_{C 6} \geq S_{C 2}\right)=0$;

$V\left(S_{C 6} \geq S_{C 3}\right)=0 ; V\left(S_{C 6} \geq S_{C 4}\right)=0.35$;

$V\left(S_{C 6} \geq S_{C 5}\right)=0.57$ (6):

Then priority weights were calculated by using Eq.

$d^{\prime}\left(C_{1}\right)=\min (1,1,1,1,1)=1$

$d^{\prime}\left(C_{2}\right)=\min (1,1,1,1,1)=1$

$d^{\prime}\left(C_{3}\right)=\min (0.83,0.83,1,1,1)=0.83$;

$d^{\prime}\left(C_{4}\right)=\min (0.083,0.083,0.24,1,1)=0.083$;

$d^{\prime}\left(C_{5}\right)=\min (0,0,0,0.76,1)=0$;

$d^{\prime}\left(C_{6}\right)=\min (0,0,0,0.35,0.57)=0$;

Priority weights form $W^{\prime}=$ $(1,1,0.83,0,083,0,0)$ vector. After the normalization $W$ vector was obtained: $(0.485,0.485,0.285,0.028,0,0)$.

From $W$ vector calculated by previous numerical procedure can be concluded that $\mathrm{C} 1$ and $\mathrm{C} 2$ criteria are most important but $\mathrm{C} 5$ and $\mathrm{C} 6$ are completely unimportant criteria. Similar results were obtained also by AHP method.

It is also possible to use the Fuzzy AHP method for comparison of alternatives according to each of criteria, but because subjective evaluation and values from Saaty's scale were not used and these matrices were calculated directly from initial information available to the decision maker, that is not necessary. Therefore, the order of alternatives for each criterion remains the same as in the AHP method (Fig. 4 and Fig. 5).

\subsection{PROMETHEE Method}

The PROMETHEE method is one of the newer methods in the field of multicriteria analyses. Authors of the PROMETHEE method are Belgians J.P. Brans, Ph. Vincke and B. Mareschal. The PROMETHEE method performs comparison and ranking of various alternatives simultaneously valued on more quantitative or qualitative criteria [15].

For solving the mentioned problem by this method, both quantitative values of criteria for each alternative as well as weights of criteria preference function should be defined. The preference function represents preference intensity of alternative $a$ in relation to alternative $b$. There are six different preference functions. In this case linear preference function with indifference area was chosen. For each of these preference functions some parameters should be defined. These parameters are: $q$-indifference treshold, defines the area within the difference of two alternative values according to some criteria is negligble for the decision maker, $p$ - preference treshold, defines the area of strict preference.

Decision maker's preference increases linearly in indifference area to strict preference area i.e. the area between tresholds $q$ and $p$ (Fig. 8).

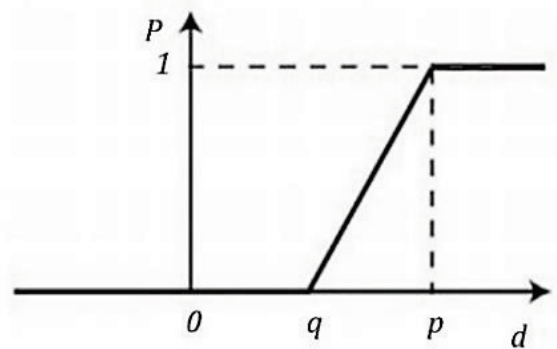

Figure $8 \mathrm{~V}$ shape preference function with indifference area

Function $P(d)$ is described by equation:

$P(d)=\left\{\begin{array}{c}0, d \leq q \\ \frac{d-q}{p-q}, q<d \leq p \\ 1, d>p\end{array}\right\}$

Also, preference index $\Pi$ should be defined as

$\Pi(a, b)=\frac{\sum_{j=1}^{n} w_{j} P_{j}(a, b)}{\sum_{j=1}^{n} w_{j}}$

where is $P_{j}(a, b)$ - preference function and $\sum_{j=1}^{n} w_{j}$ weights of criteria sum.

Preference index $\Pi(a, b)$ expresses intensity of decision maker's preference for alternative $a$ over the alternative $b$ simultaneously considering all criteria. I.e. $\Pi(a, b)$ expresses how and with what intensity $a$ dominates over $b$ regarding all criteria. Unlike that, preference index $\Pi(b, a)$ expresses how and with what 
intensity alternative $b$ dominates over alternative $a$ regarding all criteria.

For each alternative two flows should be defined: $\Phi^{+}(a)$ positive and $\Phi^{-}(a)$ negative flow. Positive flow shows how much an alternative $a$ is better than all other alternatives. It can be said that $\Phi^{+}(a)$ measures "strength" of alternative $a$ (Eq. (11)).

$$
\Phi^{+}(a)=\frac{1}{m-1} \sum_{b \in A} \Pi(a, b)
$$

Negative flow measures "a weakness" of alternative $a$ i.e. a smaller $\Phi^{-}(a)$ flow means that an alternative is better (Eq. (12)).

$\Phi^{-}(a)=\frac{1}{m-1} \sum_{b \in A} \Pi(b, a)$

Comparing positive and negative flows two sets of alternatives are obtained, one by $\Phi^{+}(a)$ and one by $\Phi^{-}(a)$. These sets are:

$\Phi^{+}(a)\left\{\begin{array}{l}a S^{+} b \text { if and only if } \Phi^{+}(a)>\Phi^{+}(b) \\ a I^{+} b \text { if and only if } \Phi^{+}(a)=\Phi^{+}(b)\end{array}\right\}$

$\Phi^{-}(a)\left\{\begin{array}{lll}a S^{-} b & \text { if and only if } \Phi^{-}(a)<\Phi^{-}(b) \\ a I^{-} b & \text { if and only if } & \Phi^{-}(a)=\Phi^{-}(b)\end{array}\right\}$

where $a S b$ means: $a$ is good like $b$ or even better.

Intersection of these two sets of alternatives results in the PROMETHEE I partial ranking of alternatives:

$a P b(a$ dominates over $b)$ if and only if $\left\{\begin{array}{lll}a S^{+} b & i & a S^{-} b \\ a S^{+} b & i & a I^{-} b \\ a I^{+} b & \text { i } & a S^{-} b\end{array}\right\}$ $a I b$ ( $a$ is indifferent with $b$ ) if and only if $a I^{+} b$ i $a I^{-} b$ $a R b$ (a i b are incomparable) otherwise

In addition to the PROMETHEE I it is possible to get the PROMETHEE II or fully ranking of alternatives. In that case net flow $\Phi$ should be calculated as difference between the positive flow and the negative flow, or as difference between "the strength" and "the weakness" of each alternative:

$\Phi(a)=\Phi^{+}(a)-\Phi^{-}(a)$

Although the decision maker can decide easier with the PROMETHEE II or fully ranking of alternatives, the PROMETHEE I or partial ranking still gives much more realistic information, especially related to incomparability that can often be of great importance for the final decision.

\section{RESULTS AND DISCUSSION}

As mentioned before, in the AHP method the overall priorities of alternatives are calculated by summing local priorities of each alternative multiplied by weights of criteria. These results are shown in Fig. 9.

Also, in the Fuzzy AHP method the overall priorities of alternatives are calculated in exactly the same way. Ranking of alternatives for examined additive manufacturing processes is the same as in the AHP method. Firstly the POLYJET process is ranked, secondly follows the SLS process, thirdly FDM and the last, fourth is 3D PRINT process. A difference here is also noticeable, considering the original AHP method, in numerical values of overall priorities of alternatives obtained by summing multiplications of local priorities and weights of criteria (Fig. 9).

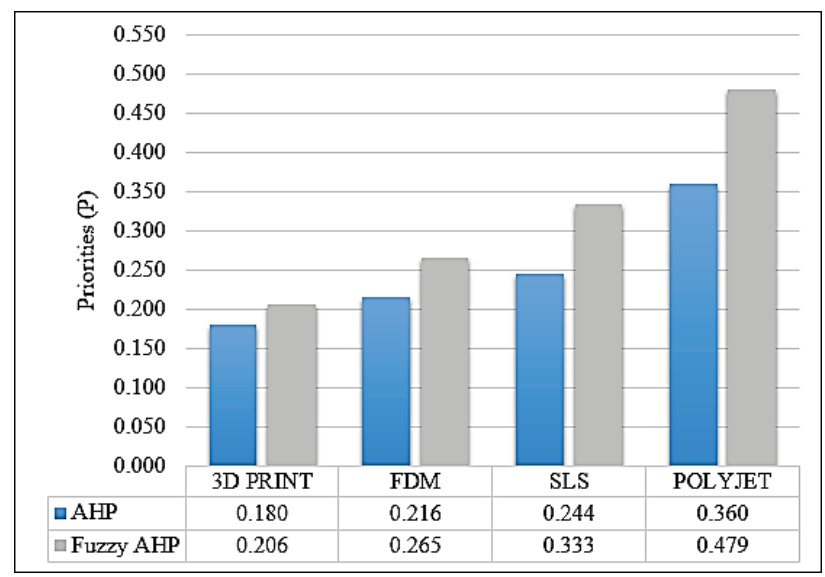

Figure 9 Overall priorities of alternatives obtained by the AHP and Fuzzy AHP method
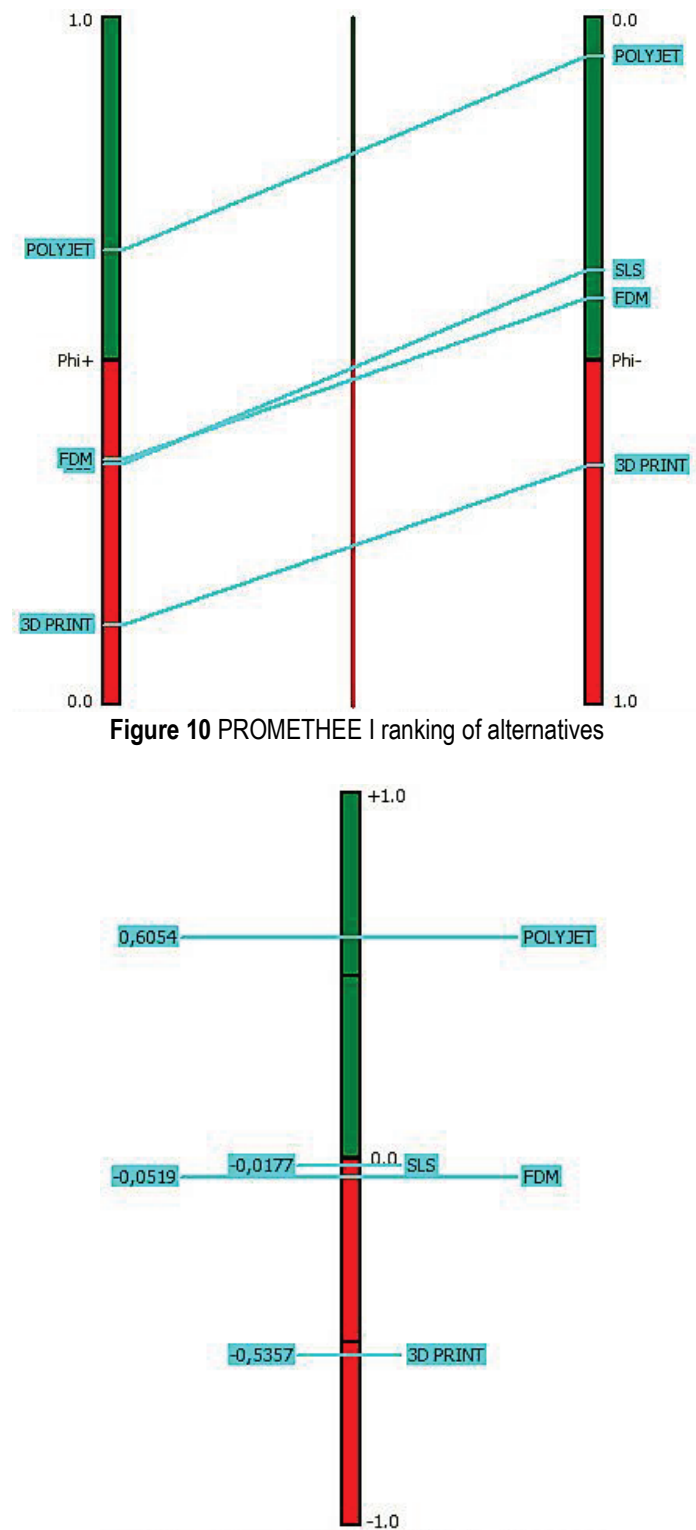

Figure 11 PROMETHEE II ranking of alternatives 


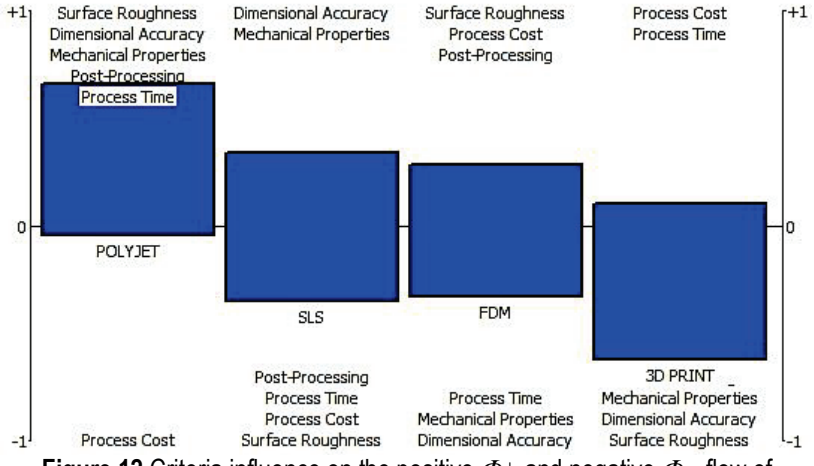

Figure 12 Criteria influence on the positive $\Phi+$ and negative $\Phi$ - flow of alternatives

For solving this problem by the PROMETHEE method, the computer software Visual PROMETHEE was used [16]. In this software it is necessary to enter weights of criteria, initial data available to the decision maker, preference function's type and numerical values of $q$ and $p$ parameters. It is obvious from the next figures that this method gives also the same rank of alternatives as two previous methods.

\section{CONCLUSION}

In this paper the model constructed in the CAD software Creo Parametric (PTC) was produced by four different additive manufacturing processes. The objective was to make a decision which of these processes is the most suitable for practical application. For comparison of these processes six different criteria and their defined quantitative values were used. In decision making process three different multicriteria decision methods were conducted. As a result of implementation of each of these methods, a rank of alternatives was obtained, i.e. additive manufacturing processes according to their priority. Finally it can be concluded that all mentioned methods give the same rank of alternatives and consequently the first choice should be the Photopolymer Jetting process, the second is the Selective Laser Sintering process, the third the Fused Deposition Modeling and on the fourth place is ranked the $3 \mathrm{D}$ Printing process. Hereby, the initial problem is successfully solved and the accuracy of solving this problem by each of the mentioned methods is proved at the same time.

Intention of this paper was to show a methodology of application of different multicriteria decision methods in solving a concrete problem of selection of an appropriate additive manufacturing process without going into details of each of these processes. Here presented criteria values and preferences of alternatives are general and subjective and the final result significantly depends on their entry in decision making process. In further work it is possible to involve more experts in the process of estimation criteria importances to get more accurate results. Also in this paper only six criteria were used so in the future to obtain more accurate overall results it is possible to evaluate more criteria, conduct more measurements on different areas of additive manufactured parts and find out more precise criteria information.

\section{Acknowledgements}

The paper has been fully supported by The Croatian Science Foundation under the project Innovative Smart Enterprise - INSENT (1353).

\section{REFERENCES}

[1] Gibson, I., Rosen, D. W., \& Stucker, B. (2010). Additive Manufacturing Technologies, Rapid Prototyping to Direct Digital Manufacturing, Springer.

[2] Vincente Borille, A. \& Oliviera Gomes, J. (2011). Selection of additive manufacturing technologies using decision methods. Rapid prototyping Technology - Principles and Functional Requirements, InTech, 29-54.

[3] Byun, H. S. \& Lee, K. H. (2005). A decision support system for the selection of a rapid prototyping process using the modified TOPSIS method. The International Journal of Advanced Manufacturing Technology, 26(1112), 1338-1347. https://doi.org/10.1007/s00170-004-2099-2

[4] Shende, V. \& Kulkarni, P. (2014). Decision support system for rapid prototyping process selection. International Journal of Scientific and Research Publications, 4(1).

[5] Panda Narayan, B., Biswal Bhusan, B., \& Deepak, B. B. L. V. (2014). Integrated AHP and fuzzy TOPSIS approach for the selection of a rapid prototyping process under multicriteria perspective. $5^{\text {th }}$ International and $26^{\text {th }}$ All India Manufacturing Technology, Design and Research Conference / Guwahati, Assam, India,.

[6] Lokesh, K. \& Jain, P. K. (2010). Selection of rapid prototyping technology. Advances in Production Engineering \& Management, 5(2), 75-84.

[7] 3D Systems, ProJet x60 Series, Professional 3D Printers, http://www.3dsystems.com/files/projet_x60_series_us_051 4_web.pdf (17.09.2015)

[8] Stratasys Direct Manufacturing, Polyjet Materials, https://www.stratasysdirect.com/materials/polyjet/ (17.09.2015)

[9] Materialise, FDM Material Properties, $\mathrm{http} / / /$ manufacturing.materialise.com/sites/default/files/publ ic/AMS/Updated\%20datasheets/ams_datasheets_fdm.pdf (17.09.2015)

[10] Shapeways, EOS Material Properties, https://www.shapeways.com/rrstatic/material_docs/mdsstrongflex.pdf (17.09.2015)

[11] Saaty, T. L. \& Vargas, L. G. (2012). Models, methods, concepts and applications of the analytic hierarchy process, Springer, New York, USA. https://doi.org/10.1007/978-1-4614-3597-6

[12] Kumar, A., Mussada, E. K., Ashif, M., Tyagi, D., \& Srivastava, A. K. (2017). Fuzzy Delphi and hybrid AHMATEL integration for monitoring of paint utilization. Advances in Production Engineering \& Management, 12(1), 41-50. https://doi.org/10.14743/apem2017.1.238

[13] Chakraborty, P. S., Sarkar, B., \& Majumdar, G. (2013). Group decision making for a manufacturing organization considering intensity of preference. Advances in Production Engineering \& Management, 8(3), 149-156. https:// doi.org/10.14743/apem2013.3.162

[14] Balli, J. \& Korukoglu, S. (2009). Operating system selection using Fuzzy AHP and TOPSIS methods. Mathematical and Computational Applications, 14(2), 119. 130. https://doi.org/10.3390/mca14020119

[15] Brans, J. P. \& Vincke, P. A. (1985). A preference ranking organization method: The PROMETHEE method for MDCM. Management Science, 31(6), 647-656. https://doi.org/10.1287/mnsc.31.6.647

[16] PROMETHEE Methods, Visual PROMETHEE 1.4 Manual, September 5, 2013. 


\section{Contact information:}

Ivan PEKO, M.Sc., Research Assistant

Faculty of electrical engineering, mechanical engineering and naval architecture

University of Split,

Ruđera Boškovića 32,

21000 Split, Croatia

E-mail: ipeko@fesb.hr

Boženko BILIĆ, PhD, Full Professor

Faculty of electrical engineering, mechanical engineering and naval architecture, University of Split,

Ruđera Boškovića 32,

21000 Split, Croatia

E-mail: bbilic@fesb.hr

Nikola GJELDUM, PhD

Faculty of electrical engineering, mechanical engineering and naval architecture,

University of Split,

Ruđera Boškovića 32,

21000 Split, Croatia

E-mail: ngjeldum@fesb.hr 